\title{
Unintended Consequences of Tele Health and their Possible Solutions
}

\section{Contribution of the IMIA Working Group on Telehealth}

\author{
S. B. Gogia', A. Maeder ${ }^{2}$, M. Mars ${ }^{3}$, G. Hartvigsen ${ }^{4}$, A. Basu', P. Abbott ${ }^{6 *}$ \\ 1 Society for Administration of Telemedicine and Healthcare Informatics (SATHI), New Delhi, India \\ 2 School of Health Sciences, Flinders University, Bedford Park, Australia \\ 3 Dept. of Telehealth, University of KwaZulu-Natal, South Africa \\ ${ }^{4}$ Norwegian Centre for E-health Research \& University of Tromso - The Arctic University of Nonway, Norway \\ 5 School of Health Sciences, University of Canterbury, Christchurch, New Zealand \\ 6 School of Nursing, University of Michigan, Michigan, USA
}

\begin{abstract}
Summary
Objectives: Assess unforeseen consequences of Telehealth and suggest solutions

Methods: An outline was created collecting all possible ill effects classified into Clinical considerations, Administrative concerns including interpersonal relations, Technical issues, Legal /

Ethical concerns and Miscellaneous. Each topic was assigned to a particular WG member to lead, gather opinion and review existing literature.

Results and Conclusion: A wide array of problems have been described. Except for technical issues, literature on this topic is scant, so this article is based more on personal experience and data collected from surveys. Much can be done to prevent such problems, such as a need for standardization with related clinical studies for devices as well as processes used for telehealth is underlined, besides evaluation of outcomes of projects undertaken.
\end{abstract}

\section{Keywords}

Telehealth; Telemedicine; eHealth; Tele-monitoring

Yearb Med Inform 2016:41-6

http://dx.doi.org/10.15265/IY-2016-012

Published online November 10, 2016

\section{Introduction}

Telehealth overcomes constraints of health reach and interaction due to time, distance as well as difficult terrains. It uses information and communication technologies to transfer medical information for the delivery of clinical and educational services [1]. Telehealth is also described as the provision of primary preventive, diagnostic, and curative health services over distance, often under asynchronous conditions. A high speed communication network is preferred with an array of modalities like Telephone, Broadband, Mobile services, Satellite etc. It may be the only method of communication in times of emergencies - such as earthquakes and floods, etc. [2].

Better lifespan and rising incidence of chronic diseases, has increased care complexity. This means longer interactions between patients and providers, as well as among providers. simultaneously increasing the need and scope for telehealth.

Telehealth is broadly classified as Synchronous or real-time using Video conferencing, or Telephonic calls as well as live feeds and Asynchronous - also called Store and Forward through SMS, Messaging services, Email etc. An emphasis on use of

* We certify that all authors contributed to the creation of this article data storage helps analytics. A third form is Tele monitoring, which means interaction with remote devices.

IMIA Telehealth Working Group constitutes of over 20 members from across the globe. All of us have been working in the telehealth arena as entrepreneurs, promoters, academicians as well as practitioners.

This invited article looks at the unintended effects of telehealth from the provider's as well as the patients' perspective. The authors of this article constitute four clinicians, one nurse and an academic besides being experts in HIT.

The Healthcare sector is one of the slowest adopters of Information technology. There have been complaints against decrease in number of patients seen, loss of reimbursement etc. by the clinicians. And of too much addiction to the screen (He is lost in his computer!) due to social media, games etc. by the patients.

We looked at issues only related to telehealth. An outline was created collecting all possible ill effects and then broadly classified into Clinical considerations, Effects on interpersonal relations Administrative concerns, Technical issues, Legal/Ethical concerns and Miscellaneous. Each topic was assigned to a particular author to lead, gather opinion and review existing literature. Some are actual issues of concern, while many only serve as arguments against adoption of Telehealth by the unwilling. A summary of the recommendations is provided in Table 1 . 


\section{Clinical Consequences}

Among required inputs for providing an opinion from a clinician, telehealth can provide only text, sight and sound. Admittedly, these are the most important ones. However, having even these to the fullest extent is a challenge. Management of a problem has to go beyond listening to the patients' voice, or "treating an image". Aside from the few who state "I have not touched the patient", clinicians can find ways and means to overcome this challenge. However, there is a higher dependence on devices some of which is beyond the control of the clinician.

Besides malfunction and miscommunication, discussed under technical considerations, there are issues of false alarms and false positives. On the other hand, clinical decision support systems as well as image analyzers can help one see beyond visual capabilities e.g. diagnosing a malaria parasite in a slide, would be an easy and useful extension [3].

A remote system means usual methods of counter-checking are missing. The identity of both, the patient as well as the provider, maybe unclear to each other. There are security issues related to patient data especially of the patient's personal information. Lastly, distance can remain a barrier for effective education and training of remote staff, posing a threat to evidence based up-to-date delivery of care. e.g. A counselling service via e-mail for children with atopic eczema bypassed the primary care level since the parents submit the pictures and questions directly to the specialists at UNN. This effected knowledge acquisition and learning by GPs about families supposedly under their care [4].

Patients may get a dependence on their Telehealth devices (e.g. checking blood pressure 3-4 times a day). A tendency to consult further on such marginal events would mean that both the clinician as well as the patient are constantly on the edge [5].

\section{Personnel}

\subsection{General}

Even while some solutions in Telehealth are entirely machine based interactions, most depend on the human interface. These supplement the current team approach to healthcare with team members located across different geographical locations. Miscommunication is possible, affecting interpersonal relations not only between care provider and patient but also between the team-members themselves. Not being in sync on a day to day basis means also that there would be lack of a proper understanding of ongoing issues of team members - health, family problems etc. All these affect quality of care.

Access to healthcare personnel also means a problem of over-reach. A patient feels free to make calls on a $24 / 7$ basis not strictly following the timelines of the clinician attends. This leads to feelings of intrusiveness [6]. Strict guidelines of who and when to call should be part of a telehealth system.

\subsection{Resistance Towards Change}

Kroken nursing home in Tromsø was the first on-line institution for elderly in Norway $[7,8]$ providing access to specialized health care, including electronic communication between nursing and supervisory physicians to exchange questions and answers via secure e-mail. In addition, it provided online lab tests and discharge summaries [4]. To facilitate this, the nurses at the nursing home were required to enter data in the electronic health record. Negativity and a resistance against new tools as well as to change of routines particularly by senior nurses close to retirement marred the overall positive results. A Change Management approach [9] may help.

\subsection{Reimbursement}

Healthcare is a service. There are no readymade products which can be sold online. With payments mostly through insurance third party mechanisms, reimbursement processes become even more difficult to streamline when using telehealth. Working through telehealth systems, at least initially, is more time consuming. It requires increased resources from both general practitioners and specialists, while benefits like savings in transportation costs and time are indirect. A system to reimburse providers for direct or indirect losses is required.

It sometimes offers competition with preference of distant providers in preference of local and home visit personnel. Nurse practitioners actually reduce the demand for GP $[7,10]$. A higher dependence on distant providers also means that the local personnel may not be available during emergencies.

On the other hand, those providing the service do gain in many ways. Examples include reporting $X$ rays [11] and remote ICU visit [12] from home.

\section{Administrative Consequences}

\subsection{Bias Towards Best Connected Demographics}

The digital divide between various groups pertaining to geography, income, education, language, faith, technology literacy and government policy among others, remains and in some instances continues to grow. There are major discrepancies between the developed and developing worlds: Internet penetration $82 \%$ vs $35 \%$, mobile broadband access $87 \%$ vs $39 \%$ and mobile phone penetration $121 \%$ vs $92 \%$ [13]. Paradoxically, the people most in need of the benefits of telehealth, namely isolated communities [14] and the rural poor are most affected by the divide. Hence, for some, instead of delivering on the promise of unifying healthcare, the care gap has widened.

Some believe that the ability of mobile phones to provide universal coverage and access to all is over hyped. Mobile phone penetration rates provided by the ITU refer to active SIM cards, roughly double that of the percentage of people with an active mobile phone [13]. However, high end connectivity like $3 \mathrm{G}$ and $4 \mathrm{G}$ is rarely provided to isolated and small rural communities due to lack of potential subscribers as they are too poor to purchase the service.

There is no simple solution to the problem as issues vary between countries, within countries and communities, and between telehealth solutions. What is needed is constant awareness of the divide and addressing it when planning and implementing scalable telehealth programs. Ignoring the divide will worsen it as implementers tend to focus on environments and scenarios most conducive to success of their program.

The 2015 Chennai floods in India resulted almost overnight in many online 
solutions for managing its general as well as health aspects. However later it was understood that besides access to food, there were issues of electricity and poor reach of networks. The better connected had better access and obviously, help could reach faster. Ironically, the areas which needed help most were ignored, at least in the initial phase.

\subsection{Incoordination of Services}

Many irrelevant solutions were offered for the Chennai floods e.g. food was sent with prescriptive advice for good washing of the same - when clean water availability was a bigger problem [15]! Online solutions for disaster relief, like Sahana [16] did help but it has been evident that there were gaps in utilizing IT to the fullest extent.

\subsection{Monitoring Who is in Charge}

Too much information accessed by many players may sometimes work at cross purposes. No easy solution exists other than restricting access. Many individuals may lay claims of being the originator. This is more likely in emergencies and disasters [17].

\subsection{Over Dependence on IT Systems}

The 2014, Ebola Virus Disease (EVD) resulted in a global alert and concerns as well as fear. In the US there was late detection of a single case but, 2 nurses contracted the disease and 18 individuals hospitalized even while the original patient died [18]. A rootcause analysis demonstrated a myriad of issues contributing to this contained crisis. A major contributing factor was the reliance on electronic communication of data between disconnected groups of stakeholders [19]. It illustrated the insufficiency of telehealth system coordination in the face of a major public health emergency. There was a false sense of security and perfection of data flow with resultant unpreparedness.

\section{Technical Challenges}

\subsection{General}

Clinical data (audio and video) is information-rich and needs high throughput of infor- mation transmission. That is expensive and technologically demanding, especially for remote and resource poor places. While basic technical and infrastructure issues imposed limitations in the early stages of Telehealth, many of these components are now commonplace (e.g. high resolution display screens and inbuilt cameras; ubiquitous and broadband telecommunications connectivity). The emphasis in the technical domain has shifted to leveraging new technical opportunities presented by continual rollout of new ICT products and services, and overcoming of legacy issues when systems cannot adapt fast enough to embrace technical changes. The areas discussed below represent three different aspects of technical challenge: in specific clinical services situations (e.g. emergency support for retrievals and first encounters), in particular care environment settings (e.g. personal monitoring in home and assisted living facilities), and in elements of human factors affecting telehealth adoption (e.g. user acceptability of how new ICT technologies are deployed).

In addition to clinical skills, a health provider placed at a remote site has to gain an additional expertise in using the tools used for Telehealth. That requires training. Adaptive learning strategy in this situation is helpful as the learner learns the mastery of tools [20]. With multiple health providers, learning has to be personalized. Devices can malfunction with less chances of recovery in a remote area where connectivity is poor. It becomes worse if there is a somewhat dependence on the device.

\subsection{Emergency Support}

Telehealth systems are geared to specific needs. Accounting for each and every possibility adds to the costs. Still, they are not a complete solution. Thus, say a falling pulse or blood pressure is detected by a remote monitor, immediate remedial measures may be difficult to come by. No telehealth system as yet can set up an $\mathrm{i} / \mathrm{v}$ line and administer fluids. Access to drugs or material needs is another issue though drones may be an answer [21].

A pilot remote alarm system for falls in the elderly activated an ambulance to reach the spot. It had false alarms, while in actual cases, local help was faster [22]. As yet, even the ultimate Tele-monitoring or robotic systems cannot replace a trained person on the spot.

\subsection{Personal Monitoring}

Telecare offers a paradigm shift for remodeling conventional care delivery mechanisms and processes in a range of different health circumstances. These maybe post-discharge recovery, rehabilitation, chronic disease self-management, independent living and aging in place, and in assisted living environments for the disabled and elderly [23]. Telecare relies on repetitive remote monitoring of the subject of care via collection and analysis of device or sensor data for a range of factors, including vital signs and other specialized physiological signals, human movement tracking, interactions with objects in the living environment, mental stimulation and sleep, eating and drinking, moods and emotions [24]. Skilled human or computer analysis of this data can provide a highly distilled information flow, leading to decision support recommendations for overall care management and for targeted events detection (e.g. adverse events such as condition exacerbation, or accidental falls).

Two circumstances confound the widespread and flexible delivery of telecare: lack of standards supporting integration of data collection components in a broader system, and lack of a universal framework for development of the underlying analytic and logic software, in a critical systems setting. Examples of standards include IEEE 11073 - applicable for devices and sensors, SNOMED-CT for health terminology, HL7 for messaging etc. Interoperability test beds - also called Connectathons, like those organized by IHE [25] help certification. Moves towards operational compatibility and interoperable data streams between products have also been made by vendor collaboration in the Continua Alliance [26]. However, adherence and compliance to standards, do increase complexity to the user interface, adding to resistance to adoption. Hence there is as yet no perfect solution.

Telehealth has been the prime mover for EHR standardization efforts [27]. Merging 
with EHRs will ensure that telehealth systems do not work in isolation and help adoption.

Systems level standardization for the functionality aspects of personal monitoring systems is necessary to assure adequate systems performance and conformance in terms of accuracy, reliability, repeatability, configurability. It would also contribute to specifying critical systems behavior though identified error conditions, failsafe processing, security and access controls [28].

\subsection{User Acceptability}

Challenges of implementation are rising with newer forms of telehealth. These, include chat groups, surrogate care personas (e.g. avatars), or simulated reality situations (e.g. games-for-health). Some are stand-alone products (e.g. mobile apps), unlike conventional telehealth which uses synchronous (video-conferencing) or asynchronous messaging [29]. Acceptance by users on a wider front needs to be achieved.

Elements contributing to user acceptability have been described by generalized models such as TAM, and include universal major factors such as perceived usefulness, perceived ease-of-use and behavioral-intention-to-use [30]. This is discussed next.

A significant perceived ease-of-use factor in these new forms of delivery is the simplicity and extent with which a user can be engaged or immersed in the technological setting. This requires design and implementation. An example is the need for navigation path awareness during movements between web pages in a health portal which provides information, assessments and training functions: users need cues such as layout or color to reassure them where they are in the knowledge space.

The attitudes of users to technology vary widely and it is difficult to generalize observations to a particular demographic or disease cohort. Readiness-to-use may be most widely achieved by offering a range of technological solutions and allowing user choice or customization of these.

WhatsApp [31], like emails previously has evolved as a simple but effective Telehealth solution. Users, are after all domain specialists and can extract need based solutions better from technology they are aware of.

\subsection{System Maintenance and Updates}

Since IT systems have a limited lifespan, a process of continuous maintenance, development and improvement is important, and needs to be planned from the beginning. For example, non-replacement of older expensive video conferencing till it was out of order, diverted attention from the patient during an emergency [4]. Clinicians have to improvise when systems fail. Reduced operation time is de-motivating and frustrating, and can even "kill" good solutions [32].

\section{Legal and Ethical Considerations}

\subsection{Cross Border Care}

Cross border telemedicine was first published in 1879 following a telephonic consultation [33]. With rising communication technology and faster transfer of sound, images, multimedia and of texts through email, messaging and lately WhatsApp, advice across borders between doctors has become routine for complex cases. The Tele radiology service "Nighthawk" which took advantage of global time differences has brought issues of cross border telehealth to the fore. X-Rays taken at night in hospitals in the US are read by radiologists in India and Australia during their normal daytime working hours [34]. Cross border telemedicine is here to stay but does require a regulatory environment.

Issues of cross border telemedicine crop up even across internal borders. In the US, doctors are required to be licensed in the state where they practice. Apart from licensure other regulatory and ethical issues include liability, jurisdiction, continuum of care, authentication, online prescription, data security, record keeping and in some instances the requirement of a prior doctor patient relationship before a telemedicine consultation [35].

Some solutions to regulatory issues are evolving. In the US, the VA has led the way, leading to the Tele-Med ACT of 2015, now under consideration in the Senate and the
House of Representatives [36]. A number of states have amended their regulations to allow peer consultation across state lines without the need for licensure in both states. Within the European Union doctors licensed in their home country may conduct telemedicine in other member nations. The Pan African eNetwork has individual agreements in place with participating countries addressing licensure, liability and jurisdiction. The newly launched BRICS telemedicine initiative will also need to address the problem.

Some suggested approaches include reciprocity of licensure for the purpose of telemedicine as in place for countries of the British Commonwealth [37]. The 2008 Bellagio Conference on eHealth recommended the development of a Global eHealth Convention which would develop an "....overarching legal and regulatory framework for eHealth, initially targeting interoperability issues and cross border provision eHealth services.." [38].

International cross border telemedicine can help correct the disparity of doctor availability, especially the inadequacy of medical specialists in the developing world.

\subsection{Care Provision by Less Trained/ Untrained Persons}

Persons who join hospitals are governed by licensing rules. While credentials of the person delivering care can be checked physically, it is harder to hold the same rigorous standards online. Doctors are an expensive component of health care provision, so incentives do exist! Even if the access point is genuine, it is difficult to assess - especially in tele calls, whether the person answering is actually the one who was allocated or an assistant/ family member, maybe even a spoof. Males are known to pose as females to answer pornography calls [39]!

Some of the reasons which drive a patient to a particular care provider are recommendation of patients, a crowd waiting, a visual inspection of the facility, his degrees etc. These are unavailable in the telehealth mode. Criteria holding sway here would more likely relate to a good online profile - read website, number of likes, online comments, etc. [40]. These have less evidence of relationship to final outcomes. They can also be falsified. 
The Hippocratic oath ordains against advertisement but applies only to those with a degree in medicine. No such rules apply for untrained persons who may benefit at the expense of regular providers. The answer lies in stricter regulation and ensuring guidelines.

\subsection{Methods of Redress for Adverse Effects}

Fixing responsibility for adverse events when a team was delivering care is normally managed internally even while one persongenerally the team leader is the front face. With multiple persons delivering distance based care, there is less chance of pinpointing the overall incharge. However there is a general opinion that, the person directly interacting with the patient is the one who should be the front face, even while he can engage the expert as a co-responder [27].

\section{Miscellaneous}

\subsection{Cost and Benefit}

Investing in a telehealth system has been considered an expensive preposition, yet to deliver on its potential. Even more so for mHealth, a simple and handy tool omnipresent globally [41, 42]. Less than ideal adoption of telehealth is related to lack of awareness of possibilities. There is also a high learning curve of implementation. Some believe that the strategy element is more important [43].

Dependence on technology and devices has added to cost of care with less effect on outcomes [44]. However, costs are constantly on a downward curve. Newer, inexpensive tools like Zoom ${ }^{\circledR}$, Teamviewer ${ }^{\circledR}$ and Skype ${ }^{\circledR e t c}$. have replaced dedicated Video conferencing equipment at many places. Those who invested in the more expensive options at the wrong time have turned cynical!

\subsection{Miscommunications}

Typos, or rather wrong words, have increased with use of auto correction facility especially in mobile devices. These are a cause of misinterpretation. The obvious solution of constant rechecking slows down processes.
As opposed to virtual consulting, a face to face interaction means that an incorrect word etc. will be mapped against facial features and gestures. Though possible in online meetings, there is a need for training. Miscommunication may occur due to a simple turning of the head, distance from the microphone, an ill focused camera, the wrong amount of light etc.

Problems get accentuated if there is poor user accessibility. Efforts are underway to correct such problems. A notable one is designing screens for the color blind [45].

\section{In Conclusion}

Several unintended consequences in the delivery of telehealth exist along with challenges affecting adoption. But these can be strategically addressed. Technological limitations predominate with a need for constant education as the tools are evolving. Thus, a dual need of evidence based provision of care along with easy contextual upskill. These are effectively addressed by use of clinical decision support systems and adaptive learning strategies.

Finally, telehealth has to remain a support system for well-defined needs and not be pushed as an engineering solution to health.

\section{Conflict of Interest}

None

\section{Acknowledgements}

We wish to thank our reviewers for helpful suggestions and Ms Spriha Gogia, senior analyst at New York City Health + Hospitals for rewriting and error correction.

Table 1 Summary of recommendations

\begin{tabular}{|c|c|c|c|}
\hline Type & Problem & Possible solution & Serious? \\
\hline Clinical & $\begin{array}{l}\text { Care provision with less than ideal information } \\
\text { or misinformation }\end{array}$ & $\begin{array}{l}\text { Clinical Decision Support using adaptive/learning } \\
\text { methods; IT should not override the clinicians }\end{array}$ & Yes \\
\hline Administrative & Cross border care (multi-jurisdictional?) & Governance co-operation & No \\
\hline Administrative & $\begin{array}{l}\text { Care provision by relatively less or untrained } \\
\text { persons }\end{array}$ & $\begin{array}{l}\text { Ensuring guidelines ("Map of Med" for } \\
\text { Telehealth) }\end{array}$ & Yes \\
\hline Technical & Lack of emergency support and retrieval care & High bandwidth connectivity; Systems interoperability & Yes \\
\hline Administrative & $\begin{array}{l}\text { Diversion of funding from more deserving } \\
\text { immediate problems (and lack of funding } \\
\text { through conventional mechanisms) }\end{array}$ & $\begin{array}{l}\text { Health economics and cost-benefit analyses; } \\
\text { Public-private funding models }\end{array}$ & No \\
\hline $\begin{array}{l}\text { Administrative/ } \\
\text { Technical }\end{array}$ & $\begin{array}{l}\text { Bias towards "best-connected" demographic } \\
\text { (including developing world) }\end{array}$ & $\begin{array}{l}\text { Scalable solutions; plafform independence of } \\
\text { services; Better penetration of connectivity }\end{array}$ & Maybe \\
\hline Clinical & $\begin{array}{l}\text { Un-usability of patient remote monitoring } \\
\text { information (including adverse events). constant } \\
\text { requirement of trained personnel, especially on } \\
\text { software upgrade }\end{array}$ & $\begin{array}{l}\text { Automated customized personal surveillance } \\
\text { systems; Enthusiasts and promoters; Help and } \\
\text { support on version change; }\end{array}$ & Yes \\
\hline Technical & Non-interoperability of monitoring devices/sensors & Standards and open systems; & No \\
\hline Technical & $\begin{array}{l}\text { User acceptability of new telehealth technology } \\
\text { (games, avatars, immersion) }\end{array}$ & $\begin{array}{l}\text { Participatory design; Interventions targeting youth; } \\
\text { Training; Incentives for learning and usage }\end{array}$ & No \\
\hline Clinical & $\begin{array}{l}\text { Services established outside ordinary protocols, } \\
\text { weak links to EHRs }\end{array}$ & $\begin{array}{l}\text { Include the service into the traditional healthcare } \\
\text { system and EHRs (if available); }\end{array}$ & № \\
\hline Personnel & $\begin{array}{l}\text { Loss of inter personal relationships (by } \\
\text { miscommunication, Misinterpretation, / } \\
\text { autotyping etc.) Loss of respect for timelines } \\
\text { (e.g. calls for help on a } 24 / 7 \text { basis) }\end{array}$ & $\begin{array}{l}\text { Rechecks, a general slowdown; } \\
\text { Strict appointment system; Guidelines }\end{array}$ & Yes \\
\hline Reimbursement & $\begin{array}{l}\text { No clear method of reimbursement. Care access } \\
\text { through unconventional means competing with } \\
\text { regular channels }\end{array}$ & $\begin{array}{l}\text { Creation of Teleheatlh related care and reim- } \\
\text { bursement protocols; engagement of insurance } \\
\text { companies; }\end{array}$ & Yes \\
\hline
\end{tabular}




\section{References}

1. Kerr K, Norris TN. A review of telehealth and its relevance to New Zealand. first. Kerr KK, Norris TN, editors. Wellington: Ministry of Health New Zealand; 2004.

2. chennai floods: Latest News, Videos and chennai floods Photos. Times of India [Internet]. Mumbai; 2015 Dec 6 [cited 2015 Dec 9]; Available from: http://timesofindia.indiatimes. com/topic/chennai-floods?gclid=Cj0KEQiAnJqzBRCW0rGWnKnckOIBEiQA6qDBanS9t iMeGlld-euR21TEJ712suwhS2hJ5ylvoqjDrkaAgGB8P8HAQ

3. Kaewkamnerd S, Uthaipibull C, Intarapanich A, Pannarut M, Chaotheing S, et al. An automatic device for detection and classification of malaria parasite species in thick blood film. BMC Bioinformatics 2012;13 Suppl 17:S18. Available from: www.ncbi.nlm.nih.gov/pubmed/23281600www. pubmedcentral.nih.gov/articlerender.fcgi?artid=PMC3521230

4. Hartvigsen G, Pedersen S. Lessons learned from 25 years with telemedicine in Northern Norway. In: NST Report No 6-2015. Norwegian Centre for Integrated Care and Telemedicine, University Hospital of North Norway; 2015. p. 405.

5. Radhakrishnan K. Unintended Consequences: How Telehealth Can Fail to Manage Chronic Diseases [Internet]. Longhorn Nursing. [cited 2015 Dec 14]. Available from: http://sites.utexas. edu/nursing/2013/04/02/unintended-consequences-how-telehealth-can-fail-to-manage-chronic-diseases/

6. Telephone Consultations; Telephone Consulting. Patient [Internet]. 2009 [cited 2015 Dec 14]; Available from: http://patient.info/doctor/telephone-consultations

7. Abelsen LR, Vestad A, Nygård, D, Skipenes E, Eriksen HØ, Nohr LE, et al. Ses@m Tromsø: eventyrlige muligheter for pleie- og omsorgstjenesten. (Ses@m Tromsø: adventurous opportunities for nursing and care services.) NST-report no 10. Ses@m Tromse; 2006.

8. Nyheim B. Telemedisin: Kroken sykehjem er på nett. (Telemedicine: Kroken nursing home is online). Sykepleien. 2005;93(9):2.

9. Eastman D, McCarthy C. Embracing change: Healthcare technology in the 21st century. Nurs Manage_2012 Jun;43(6):52-4.

10. Eastman D, McCarthy C. Embracing change: Healthcare technology in the 21st century. Nurs Manage 2012 Jun;43(6):52-4.

11. Kalyanpur A. Improvements of patient care through Teleradiology. Healthcare Executive 2012;30-4.

12. Kannan R. No need to visit, you can see patients through "I-See-U." The Hndu [Internet]. Chennai; 2013 Oct 2;8. Available from: http://www. thehindu.com/news/national/tamil-nadu/noneed-to-visit-you-can-see-patients-through-iseeu/ article5190555.ece

13. Statistics [Internet]. [cited 2015 Dec 13]. Available from: http://www.itu.int/en/ITU-D/Statistics/Pag- es/stat/default.aspx

14. Chatterjee P. Death Rate goes up with Distance from District Hospital. Indian Express [Internet]. Aug;1. Available from: http://epaper.indianexpress.com/567918/Indian-Express/19-August2015\#clip/6256409/91cf622a-8bc8-4d94-9a912958570dc683/1226:347.9999999999999

15. FloodRelief-HEALTHEDUCATIONPROJECT1. 2015.

16. SahanaEden [Internet]. SahanaWiki. 2012 [cited 2015 Dec 14]. Available from: http://eden.sahanafoundation.org/wiki

17. Gogia S B. Providing Tele mental health services after disasters - based on the Post Tsunami experience. In: Scupala Ada, editor. Cases in Managing E Services [Internet]. Pennsylvania USA: IGI Global; 2009. p. 238-52. Available from: http:// www.igi-global.com/bookstore/chapter.aspx?titleid $=6425$

18. Failures of Dallas hospital during Ebola crisis detailed in new report - The Washington Post [Internet]. [cited 2015 Dec 14]. Available from: https://www.washingtonpost.com/news/to-yourhealth/wp/2015/09/04/failures-of-dallas-hospitalduring-ebola-crisis-detailed-in-new-report/

19. Cortese D, Abbot P, Chassin M, Lyon MG, Riley WG. The Expert Panel Report to Texas Health Resources Leadership on the 2014 Ebola Events. 2014.

20. Doarn CR, Merrell RC. A Roadmap for Telemedicine: Barriers Yet to Overcome. Telemed J E Health 2008;14(9):861-2.

21. Dronelife News. How Drones Can Have A Place In Health Care. Healthc News [Internet]. 2014; Available from: http://dronelife.com/2014/10/20/ drones-can-place-health-care/

22. Leauhatong T. A New System for Detecting and Alerting Falling. In: Asia Pacific Telemedicine Conference. Shanghai: APSCO; 2015.

23. Koch S. Home telehealth - current state and future trends,. Int Med Informatics. 2006;75(8):565-76.

24. Pantelopoulos A, Bourbakis NG. A survey on wearable sensor-based systems foir health monitoring and prognosis. IEEE Trans Syst Man, Cybern Part C Appl Rev 2010;40(1):1-12.

25. IHE Gazelle eHeallth Interoperability framwork [Internet]. Available from: https:/gazelle.ihe.net/

26. Wartena F, Muskens J, Schmitt L. Continua: the impact of a personal telehealth ecosystem. In: IEEE International Conference on eHealth, Telemedicine, and Social Science. 2009. p. 13-8.

27. MOHFW GOI. EMR/EHR Standards for India [Internet]. New Delhi; 2013 [cited 2015 Aug 1]. Available from: http://mohfw.nic.in/showfile. php?lid=1672

28. Lee I, Pappas GJ, Cleaveland R, Hatcliff J, Krogh $\mathrm{BH}$, Lee P, et al. High-confidence medical device software and systems. Computer (Long Beach Calif) 2006;39(4):33-8.

29. Lupton D. Critical perspectives on digital health technologies. Sociol Compass 2014;8(12):1344-59.

30. Venkatesh V, Bala H. Technology acceptance model 3 and a research agenda on interventions. Decis Sci 2008:39(2):273-315.

31. Graziano F, Maugeri R, Iacopino DG. Whatsapp versus Telemedicine. Neuroreport
2015;26(10):602-3

32. Norum J, Pedersen S, Størmer JL, Rumpsfeld M, Stormo A, Jamissen N, et al. Prioritisation of telemedicine services for large scale implementation in Norway. J Telemed Telecare 2007;13:185-92.

33. Aronson SH, Mackenzie C, Bell AG. The Lancet on the telephone 1876-1975. Med Hist 1977;21:69-87.

34. Law Journal Library - HeinOnline.org [Internet]. [cited 2015 Dec 13]. Available from: http:// heinonline.org/HOL/Page?handle=hein.journals/ jlah20\&div=16\&g_sent=1\&collection=journals

35. dod telemedicine licensure - Google Search [Internet]. [cited 2015 Dec 13]. Available from: https://www.google.com/search?q=VA+telemedicne + licensure \&ie $=$ utf- $8 \&$ \&oe $=$ utf- $8 \#$ newwindow $=1 \&$ safe $=0 f f \& q=$ dod + telemedicine + licensure

36. Will the TELE-MED Act of 2015 Really Change Licensure Rules? Health Care Law Today [Internet]. [cited 2015 Dec 13]. Available from: https://www. healthcarelawtoday.com/2015/08/26/will-the-telemed-act-of-2015-really-change-licensure-rules/

37. Commonwealth Health Ministers Book 2008: E-Health, Book 2008 [Internet]. Commonwealth Secretariat; 2008 [cited 2015 Dec 13]. 211 p. Available from: https://books.google.co.za/books/about/ Commonwealth_Health_Ministers_Book_2008. $\mathrm{html}$ ?id=7jYfAQAAIAAJ\&pgis=1

38. Gerber T, Olazabal V, Brown K, Pablos-Mendez A. An Agenda For Action On Global E-Health. Health Aff 2010;29(2):233-6.

39. Spoofing porn sites..anyone experience? Pirate 4x4.Com : 4x4 and Off-Road Forum [Internet]. [cited 2015 Dec 14]. Available

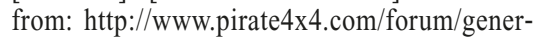
al-chit-chat/422770-spoofing-porn-sites-anyone-experience.html

40. Practo and rating systems $\mid$ Bespoke Data Insights [Internet]. [cited 2015 Dec 14]. Available from: $\mathrm{http}$ //bespokedata.in/practo-and-rating-systems/

41. Market Research Report - 25583. mHealth Market - Global Mobile Health Industry Analysis, Size, Share, Growth, Trends and Forecast, 2012 - 2018 [Internet]. Transparency Market Research; 2013. Available from: http://www.giiresearch.com/ report/tsm258823-mhealth-market-global-mobilehealth-industry.html

42. Global Teledensity Hits 100\%. Mobile payments world. 2015.

43. de Assis Moura Jr. L. Embracing Strategies for eHealth. Yearb Med Inform 2015 Aug 13;10(1):1.

44. Gogia SB. Planning for Telemedicine in Community Health Care - the Road Ahead. In: Agarwala K $\mathrm{N}$, editor. IIIT-A Series on E-Governance:3rd book: IT and Rural Health. Allahabad, Indian: Mcmillan; 2009. p. 103-20.

45. Bhatia S. Proof your EMR for color blind Clinicians [Internet]. 2016 [cited 2016 May 20]. Available from: http://blog.saurabhbhatia.com/2016/05/ proof-your-emr-for-color-blind.html

Correspondence to:

WG Chairperson Shashi Bhushan Gogia

E-Mail: gogia7@gmail.com 